\title{
Pelatihan Peningkatan Kewirausahaan Ukm Keripik Dan Minuman Desa Yosowilangun Lor Kecamatan Yosowilangun
}

\author{
Neny Tri Indrianasari \\ Program Studi Akuntansi, STIE Widya Gama Lumajang \\ indriana85@gmail.com
}

\begin{abstract}
Abstrak
Salah satu cara untuk meningkatkan jumlah usaha di lingkungan Yosowilangun Lor khususnya adalah dengan meningkatkan sektor kewirausahaan di sektor makanan dan minuman yaitu produk keripik dan jamu. Akan tetapi terdapat permasalahan pada umumnya yang mengitari pengusaha-pengusaha tersebut yang menghambat pertumbuhannya meliputi beberapa hal mendasar seperti; lemahnya mental berwirausaha, ketertutupan dan ketidakjelasan entitas, akuntabilitas, pemasaran, keterikatan yang kuat pada tradisi sehingga kurang tanggap dan adaptif terhadap tuntutan perubahan, ketertinggalan teknologi, dan cenderung mengabaikan mutu. Dengan demikian kegiatan Pengabdian Masyarakat diselenggarakan berupa pelatihan mengenai pelatihan bidang pemasaran dan konsep kewirausahaan. Metode pelaksaan kegiatan terdiri dari tiga tahap. Pertama tahap persiapan, Tahap kedua yaitu tahap pelaksanaan program berupa pelatihan. Tahap ketiga yaitu tahap evaluasi dan pelaporan.
\end{abstract}

Kata Kunci : UKM, kewirausahaan, manajemen

\begin{abstract}
Abstrack
One way to increase the number of businesses in the Yosowilangun Lor environment in particular is by increasing the entrepreneurship sector in the food and beverage sector, namely chips and herbal products. However, there are general problems that surround these entrepreneurs which hamper their growth, including some basic things such as; weak mental entrepreneurship, closure and obscurity of the entity, accountability, marketing, strong attachment to tradition that is lss responsive and adaptive to the demands of change, technological lagging, and tends to ignore quality. Thus the Community Service activities were held in the form of training on marketing training and entrepreneurial concepts. The method of implementing activities consists of three stages. First is the preparation stage, the second stage is the program implementation stage in the form of training. The third stage is the evaluation and reporting stage.
\end{abstract}

Keywords: UKM, entrepreneurship, management

\section{PENDAHULUAN}

Kebijakan UKM umumnya bertujuan untuk mendukung upaya untuk mengurangi kemiskinan, kesenjangan, penciptaan lapangan kerja, meningkatkan ekspor dan merangsang pertanian dan daerah pedesaan, yang menjadi prioritas pembangunan nasional pada tahun 2006. Dalam konsep ini, usaha kecil dan menengah (UKM) Untuk memberikan kontribusi yang signifikan terhadap penciptaan lapangan kerja, meningkatkan ekspor dan meningkatkan daya saing, sementara pengembangan usaha kecil diarahkan untuk berkontribusi pada pendapatan masyarakat berpenghasilan rendah, khususnya di sektor pertanian dan pedesaan. 
Kinerja nyata yang dihadapi oleh sebagian besar perusahaan, terutama usaha mikro, kecil dan menengah di Indonesia, yang paling menonjol adalah tingkat produktivitas rendah, nilai tambah rendah, dan produk berkualitas rendah. Meskipun diakui juga bahwa usaha mikro dan kecil menjadi peluang kerja bagi sebagian besar pekerja di Indonesia, kontribusi terhadap GNP tergolong rendah. Ini karena usaha mikro dan kecil, khususnya usaha mikro dan sektor pertanian (yang menyerap banyak tenaga kerja), memiliki produktivitas yang sangat rendah. Jika upah digunakan sebagai produktivitas, upah rata-rata di perusahaan kecil dan kecil biasanya lebih rendah daripada upah minimum. Persyaratan ini mencerminkan produktivitas yang lebih rendah dari sektor kecil dan kecil dibandingkan dengan perusahaan besar.

Salah satu cara untuk meningkatkan jumlah usaha di lingkungan Yosowilangun Lor khususnya adalah dengan meningkatkan sektor kewirausahaan di sector makanan dan minuman yaitu produk keripik dan jamu. Akan tetapi terdapat permasalahan pada umumnya yang mengitari pengusaha-pengusaha tersebut yang menghambat pertumbuhannya meliputi beberapa hal mendasar seperti; lemahnya mental berwirausaha, ketertutupan dan ketidakjelasan entitas, akuntabilitas, pemasaran, keterikatan yang kuat pada tradisi sehingga kurang tanggap dan adaptif terhadap tuntutan perubahan, ketertinggalan teknologi, dan cenderung mengabaikan mutu.

Permasalahan ini mencuat kepermukaan sejalan dengan kondisi lingkungan bisnis yang semakin kompleks dan penuh ketidakpastian pada akhir-akhir ini dan ke depan. Oleh karena itu perlu diupayakan program berkelanjutan untuk menumbuhkan mentalitas dan budaya bisnis, kreativitas disain produk, penyerapan kemajuan tehnologi, serta pengetahuan dan ketrampilan manajerial yang sesuai dengan tuntutan lingkungan bisnis yang terus berubah.

Ada beberapa permasalahan yang dihadapi oleh UKM di Desa Yosowilangun Lor antara lain kurangnya permodalan yang dimiliki, terbatasnya akses pemasaran, terbatasnya Sumber Daya Manusia., kurangnya inovasi di dalam produk dan sebagian besar belum melakukan pembukuan sederhana dalam usahanya.

Ukuran keberhasilan program Pengabdian Masyarakat UKM Keripik dan Minuman adalah dengan tercapainya target kegiatan ini, adapun target kegiatan ini adalah peningkatan pemahaman peserta pelatihan tentang kewirausahaan baik dari sisi manajemen keuangan, manajemen pemasaran, dan inovasi.

Kegiatan Pengabdian Masyarakat ini diharapkan memberikan luaran bagi mitra sebagai berikut perluasan pasar diluar daerah, pendampingan promosi online, inovasi varian produk serta pembukuan keuangan sederhana.

\section{METODE PELAKSANAAN}

Ada beberapa metode pendekatan yang digunakan dalam pelaksanaan program, meliputi:

a. Pelatihan

Program pengabdian kepada masyarakat dilaksanakan dalam bentuk pelatihan kepada mitra pelaku usaha UKM di Desa Yosowilangun Lor Kecamatan Yosowilangun. Pelatihan tersebut berupa pemamparan materi kepada mitra terkait permasalahan yang dihadapi mitra yaitu aspek kewirausahaan dan aspek manajemen. Materi yang akan disampaikan diharapkan dapat memberikan peningkatan pengetahuan dan pemahaman untuk selanjutnya dapat diterapkan oleh mitra dalam kegiatan usaha.

b. Diskusi 
Setelah materi selesai dipaparkan, dilanjutkan dengan diskusi berupa tanya jawab antara pemateri dengan peserta. Diskusi dilakukan agar peserta lebih memahami materi yang telah disampaikan. Melalui diskusi, pelatihan tidak hanya sekedar transfer knowledge saja melainkan dapat sharing pengalaman maupun permasalahan yang sedang dihadapi mitra.

\section{HASIL DAN PEMBAHASAN}

Kegiatan pengabdian masyarakat ini terdiri dari dua sesi pelatihan yang terjadi dengan para pelaku UKM beserta aparat desa Yosowilangun Lor. Metode pelatihan merupakan gabungan antara pelatihan bidang pemasaran dan konsep kewirausahaan. Pemberian pembekalan bidang pemasaran diberikan dengan bahan pemasaran produk secara umum, serta tentang kewirausahaan serta bagaimana agar dapat bekerja dengan SMART. Pada saat pemberian pelatihan tidak hanya cerita tentang teori tetapi lebih terhadap pembahasan masalah yang mereka hadapi selama ini. Untuk bidang kewirausahaan, ruang pelatihan dibagi menjadi untuk para pelaku usaha yang memproduksi barang, jasa, serta berdagang atau berjualan. Mereka dapat membahas masalah-masalah yang mereka hadapi selama ini.

Acara pelatihan dilanjut dengan diskusi atau sharing, tentang masalah-masalah yang dihadapi oleh pelaku UKM dikaitkan dengan kebutuhan pelatihan untuk menyelesaikan masalah yang ada. Ternyata masalah yang paling banyak memang masalah pada bidang keuangan, baik itu pada pengelolaannya yang masih tercampur akan pengelolaan keuangan keluarga serta keuangan usaha, kurangnya modal, sulitnya mendapatkan jejaring dengan pihak lembaga keuangan atau perbankan. Untuk bidang pemasaran masalah yang mereka hadapi adalah masalah dari sulitnya mendapatkan tempat untuk berjualan, sulitnya memperluas pasar, ketidaktahuan untuk melakukan alat promosi dan pentingnya pengembangan produk. Selain dari itu pada bidang operasi adalah sulitnya mendapatkan supplier atau pemasok yang lokasinya dekat dengan tempat mereka berusaha serta sulitnya mendapatkan barang.
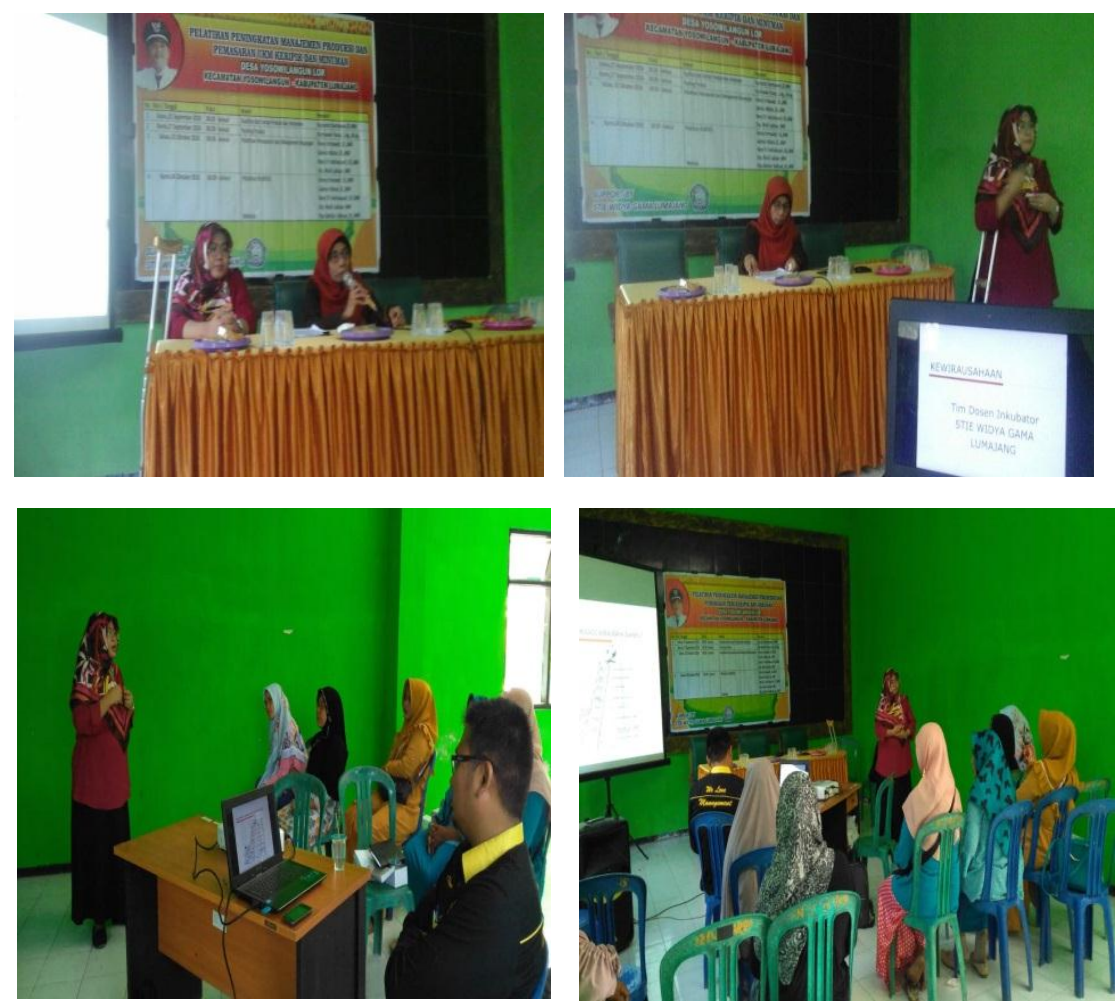

Gambar 1. Pemaparan Materi Kepada Peserta 


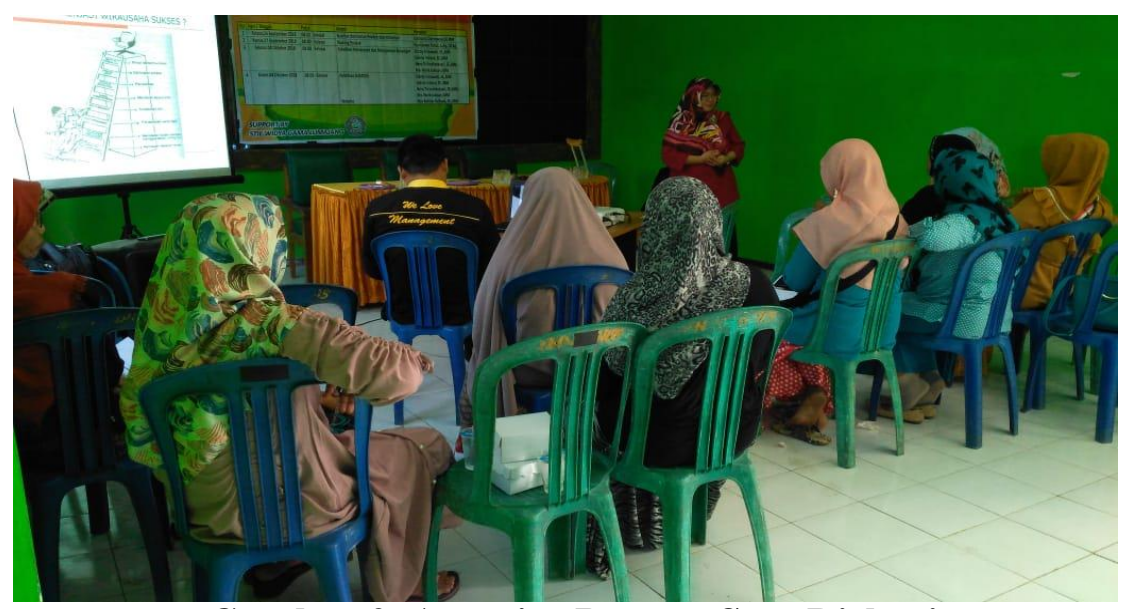

Gambar 2. Antusias Peserta Saat Diskusi

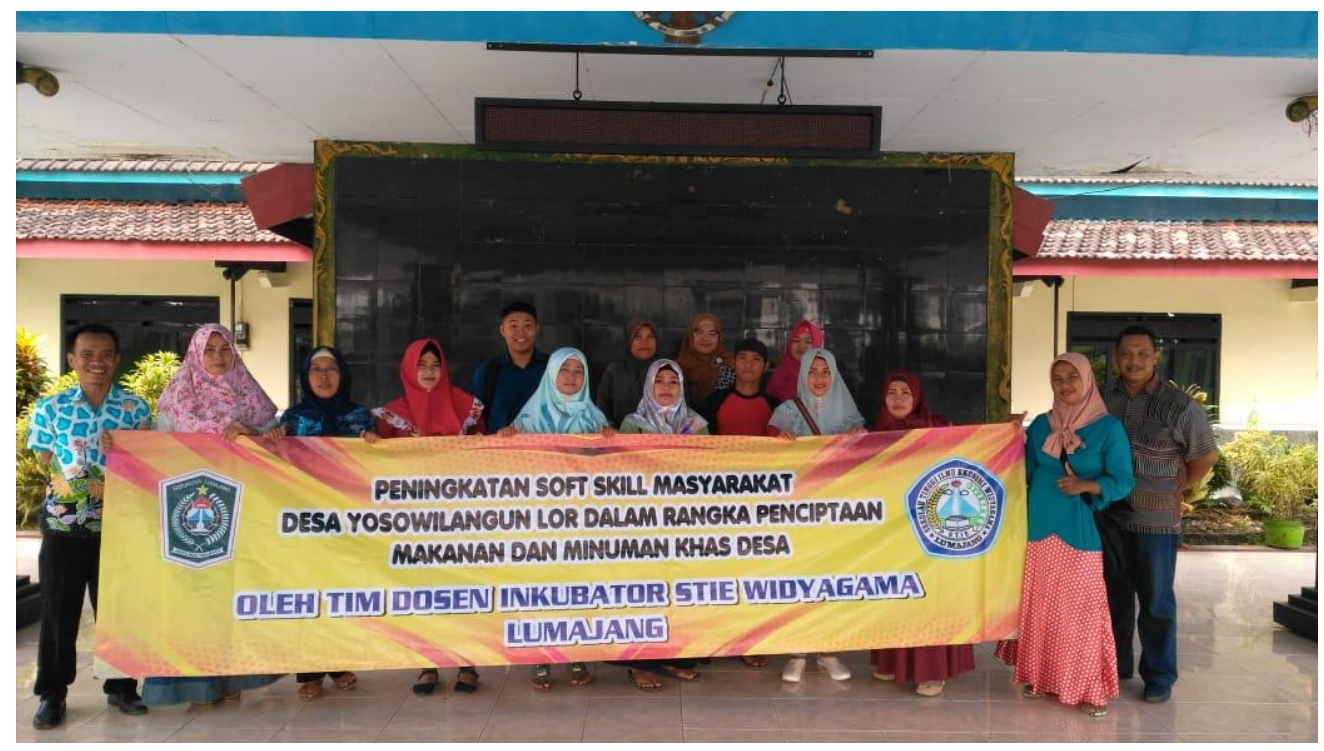

Gambar 3. Tim Pengabdian Masyarakat dengan Peserta

\section{Evaluasi Program}

Evaluasi program dilakukan untuk mengetahui hasil dan progress dari pelaksanaan program yang telah direncanakan. Evaluasi ini dilakukan dengan cara membandingkan kondisi mitra sebelum program dilaksanakan dan kondisi mitra setelah program dilaksanakan. Secara rinci, evaluasi program dapat dilihat berdasarkan tabel berikut

\section{Tabel 1}

Evaluasi Pelaksanaan Pengabdian Masyarakat

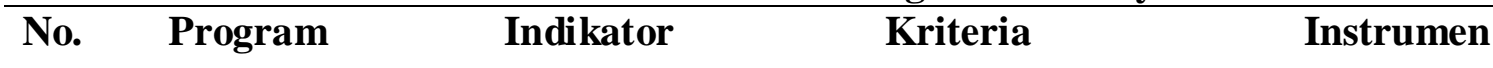




\begin{tabular}{|c|c|c|c|c|c|}
\hline 1. & $\begin{array}{l}\text { Pelatihan } \\
\text { Pengenalan } \\
\text { Kewirausahaan }\end{array}$ & $\begin{array}{l}\text { Pemahaman mitra } \\
\text { mengenai ciri-ciri } \\
\text { wirausahawan }\end{array}$ & 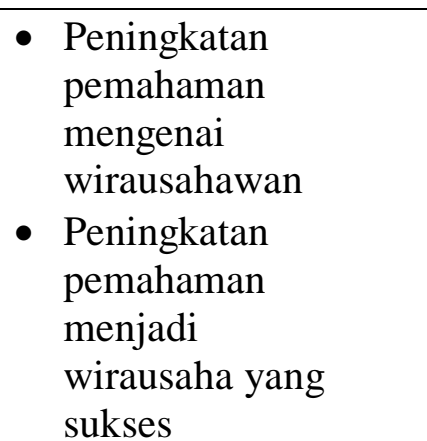 & $\begin{array}{l}\square \\
\square\end{array}$ & $\begin{array}{l}\text { Observasi } \\
\text { Wawancara }\end{array}$ \\
\hline 2. & $\begin{array}{l}\text { Pelatihan dalam } \\
\text { inovasi dan } \\
\text { kemasan } \\
\text { produk }\end{array}$ & $\begin{array}{l}\text { Pemahaman dan } \\
\text { penerapan mitra } \\
\text { mengenai inovasi dan } \\
\text { kemasan produk }\end{array}$ & $\begin{array}{l}\text { - Peningkatan } \\
\text { pemahaman inovasi } \\
\text { dan kemasan produk }\end{array}$ & $\begin{array}{l}\square \\
\square\end{array}$ & $\begin{array}{l}\text { Observasi } \\
\text { Wawancara }\end{array}$ \\
\hline 3. & $\begin{array}{l}\text { Pelatihan dalam } \\
\text { manajemen } \\
\text { pemasaran }\end{array}$ & $\begin{array}{l}\text { Pemahaman dan } \\
\text { penerapan mitra } \\
\text { mengenai pemasaran } \\
\text { produk secara online }\end{array}$ & $\begin{array}{l}\text { Peningkatan } \\
\text { pemahaman } \\
\text { mekanisme } \\
\text { strategi } \\
\text { pemasaran } \\
\square \text { Penerapan } \\
\text { strategi } \\
\text { pemasaran } \\
\text { dalam kegiatan } \\
\text { usaha }\end{array}$ & $\begin{array}{l}\square \\
\square\end{array}$ & $\begin{array}{l}\text { Observasi } \\
\text { Wawancara }\end{array}$ \\
\hline 4. & $\begin{array}{l}\text { Pelatihan dalam } \\
\text { manajemen } \\
\text { keuangan }\end{array}$ & $\begin{array}{l}\text { Pemahaman dan } \\
\text { penerapan mitra } \\
\text { mengenai pembukuan } \\
\text { sederhana }\end{array}$ & $\begin{array}{l}\square \\
\text { Peningkatan } \\
\text { pemahaman } \\
\text { pembukuan } \\
\text { sederhana dalam } \\
\text { kegiatan usaha }\end{array}$ & $\begin{array}{l}\square \\
\square\end{array}$ & $\begin{array}{l}\text { Observasi } \\
\text { Wawancara }\end{array}$ \\
\hline
\end{tabular}

\section{KESIMPULAN}

Berdasarkan hasil pelaksanaan kegiatan yang telah dilakukan, maka terdapat beberapa hal yang dapat disimpulkan dari kegiatan Pengabdian Masyarakat ini, yaitu:

1. Pengetahuan dan pemahaman peserta pelaku usaha kecil dan binaan koperasi masih rendah terkait dengan semangat berwirausaha dan bagimana mengelola keuangan

2. Pelatihan yang dilaksanakan mampu meningkatkan jiwa wirausaha dan motivasi para pelaku usaha dalam menjalankan usaha bisnisnya dengan baik dan optimal..

Berdasarkan kegiatan yang telah dilakukan maka dapat diajukan beberapa saran sebagai berikut:

1. Adanya kegiatan sejenis hendaknya selalu diselenggarakan secara periodik sehinga dapat meningkatkan keterampilan dan kemandirian UMKM.

2. Minimnya biaya operasional kegiatan menjadikan inovasi produk dan kemasan terbatas.

3. Penambahan waktu untuk praktek menggunakan media online sebagai sarana promosi untuk peningkatan penjualan.

\section{DAFTAR PUSTAKA}


Santoso, Ivan Rahmat. 2018. Pelatihan Kewirausahaan Bagi Pelaku Umkm Di Kelurahan Biyonga Kecamatan Limboto Kabupaten Gorontalo. Gorontalo : Universitas Negeri Gorontalo.

Satyarini, Ria. 2013. Pengabdian bagi Pelaku Usaha di Sekitar Unpar. Bandung: Jurnal Lembaga Penelitian dan Pengabdian Masyarakat Universitas Katolik Prahayangan.

Sukmadewi, Yudhitiya Dyah. 2017. Sosialisasi Legalitas Dan Manajemen Usaha Bagi Pelaku Usaha Umkm Di Kecamatan Pedurungan Kota Semarang. Semarang : Universitas Semarang. 